\title{
Utilization of waist circumference to determine type 2 diabetes risk among normal and overweight populations
}

\begin{abstract}
It is well known that overall obesity and excess central adiposity is associated with an increased risk of developing prediabetes and Type 2 diabetes. Because diabetes is found in epidemic proportions and complications related to it are a leading cause of death in the United States, it is important to develop a full understanding of the risk factors and their reduction with lifestyle education. BMI is a common indicator used for risk factor assessment with those being overweight or obese having the highest risk. Similarly, those possessing an elevated waist circumference increase risk. Recent data from the National Diabetes Statistics Report suggest that approximately $12.5 \%$ of those diagnosed with diabetes are of a normal body mass index $\left(\mathrm{BMI}<25 \mathrm{~kg} / \mathrm{m}^{2}\right)$. Little is known if normal or slightly overweight individuals classified by BMI have a waist circumference that can predict insulin resistance, prediabetes, or risk of developing Type 2 diabetes. Therefore the purpose of this study was to examine if there is a relationship between waist and hip measurements and the risk for developing Type 2 diabetes in non-obese persons.
\end{abstract}

Keywords: type 2 diabetes, body mass index, overweight, obese, waist circumference, fasting plasma glucose
Volume 8 Issue I - 2018

\author{
Esdaile $\mathrm{H}$,Young JC and Kruskall LJ \\ University of Nevada, USA
}

Correspondence: Kruskall LJ, University of Nevada, Las Vegas, 4505 S. Maryland Pkwy Box 453026 Las Vegas, NV 89154-3026, Tel 7022740370,Email laura.kruskall@unlv.edu

Received: January 26, 2018 | Published: February 05, 2018
Abbreviations: BMI, body mass index; WC, waist circumference; HC, hip circumference; W:HR, waist-to-hip ratio; FBG, fasting blood glucose; WHO, world health organization

\section{Introduction}

Prevalence of prediabetes and Type 2 diabetes is rapidly increasing in the United States, and has reached epidemic levels. Currently, 30.3 million adults, or $1 / 10$ of the population, in the U.S. are classified as diabetic, and it has been estimated that this incidence will increase to $1 / 5$ of U.S. adults by $2025 .{ }^{1}$ Currently, 86 million adults in the United States are classified as prediabetic, and approximately $90 \%$ of those adults are unaware of their condition. ${ }^{1,2}$ Since complications due to diabetes are a top cause of death in the United States, reducing the risk of developing either of these conditions is prudent. The overall relationship between obesity and increased risk for developing prediabetes and Type 2 diabetes has been well established. Risk factors related to overweight and obesity include having a BMI $\geq 25 \mathrm{~kg} / \mathrm{m}^{2}$ (overweight) or $\geq 30 \mathrm{~kg} / \mathrm{m}^{2}$ (obese) or possessing excess central body fat deposition. It is well established that elevated waist circumference increases the risk of Type 2 diabetes by greater than two-fold. ${ }^{3}$ Other risk factors for diabetes include physical inactivity, immediate relatives with Type 2 diabetes, being of African American, Alaska native, American Indian, Asian American, Hispanic/Latino, or Pacific Island American ethnicities, previous diagnosis of gestational diabetes, high blood pressure, HDL cholesterol levels below $35 \mathrm{mg}$ / $\mathrm{dL}$, triglyceride levels above $250 \mathrm{mg} / \mathrm{dL}$, diagnosis of Polycystic Ovarian Syndrome or cardiovascular disease. ${ }^{4}$

Recent data from the National Diabetes Statistics Report suggest that approximately $12.5 \%$ of those diagnosed with diabetes are of a normal body mass index $\left(\mathrm{BMI}<25 \mathrm{~kg} / \mathrm{m}^{2}\right){ }^{5}$ A 2016 study by Mainous and colleagues observed the prevalence of prediabetes and abdominal obesity among adults aged 20years or older, within a healthy weight range (BMI: $\left.18.5-24.99 \mathrm{~kg} / \mathrm{m}^{2}\right){ }^{6}$ They concluded that $18.5 \%$ of subjects $\geq 20$ years old were classified as prediabetic $\left(\mathrm{HbA}_{1 \mathrm{c}}\right.$ levels between $5.7 \%$ and $6.4 \%$ ), and $33.1 \%$ of subjects $\geq 45$ years received the same classification. ${ }^{7}$ Fortunately, at 45years, individuals are recommended to receive diabetes screening, however this is not true for those $<45$ years with normal BMI and increased waist circumference. In the same study, it was observed that $7.6 \%$ of subjects $\geq 20$ years showed unhealthy waist circumference measurements $(>102 \mathrm{~cm}$ for men, $>88 \mathrm{~cm}$ for women), while $33.7 \%$ of subjects $\geq 45$ years showed unhealthy abdominal obesity.

The current guidelines make it less likely for physically lean (defined by BMI), but metabolically obese individuals with undiagnosed prediabetes to receive intervention and prevent the development of Type 2 diabetes. Regardless of perceived healthfulness due to a "normal" BMI measurement, risk can still be elevated in lean individuals that possess excess visceral body fat (21). Because of the strong correlation between visceral body fat and waist circumference, it is possible that waist circumference is a better indicator of Type 2 diabetes risk, than a BMI measurement. Utilizing waist circumference as a measurement of central adiposity in a clinical setting may help to identify more of these at risk individuals, and allow them the option of lifestyle intervention. Data assessing risk factors for developing diabetes in normal weight persons are not abundant. The purpose of this study was to determine if there is a relationship between waist and hip measurements and the risk for developing Type 2 diabetes in non-obese persons.

\section{Materials and methods}

\section{Subjects}

All subjects were between the ages of 18 and 50years, not diagnosed with chronic disease, free of unresolved medical conditions, 
and weight stable in the past 3 months $(+/ 3 \mathrm{~kg})$. Individuals that were underweight $\left(\mathrm{BMI}<18.5 \mathrm{~kg} / \mathrm{m}^{2}\right)$, obese $\left(\mathrm{BMI}>30 \mathrm{~kg} / \mathrm{m}^{2}\right)$, pregnant, or have recently lactated (past 6months) were excluded. Written Consent was obtained from all subjects prior to participation. This study was approved by the University Institutional Review Board.

\section{Anthropometric assessment}

Participants wore lightweight clothing, and no shoes. Height was measured using a stadiometer to the nearest $0.1 \mathrm{~cm}$. Weight was measured using an in body scale to the nearest $0.01 \mathrm{~kg}$. Waist circumference (WC) and hip circumference (HC) were measured using a steel measuring tape following WHO guidelines. ${ }^{7}$ Waist circumference was measured just above the uppermost lateral border of the right ileum, and hip circumference was measured at the maximum protuberance of the buttocks. BMI was calculated as weight $(\mathrm{kg})$ divided by height squared $\left(\mathrm{m}^{2}\right)$, and waist to hip ratio (W: HR) was calculated as waist circumference $(\mathrm{cm})$ divided by hip circumference $(\mathrm{cm})$.

\section{Laboratory assessment}

Fasting blood glucose (FBG) was measured following an overnight (8-12hour) fast. The blood sample was expressed using Acti-Lance ${ }^{\circledR}$ Lite sterile lancet, following cleaning of the fingertip using an alcohol wipe. Blood glucose was measured with Bayer Contour-Next Blood Glucose meter and test strips. Blood glucose meter was calibrated per manufacturer instructions prior to each measurement.

\section{Statistical analysis}

Statistical Analysis was performed using Prism (version 7.0d). Linear regression models were used to determine regression coefficients of WC, BMI, and W: HR for the prediction of FBG. Pearson's correlation was used to assess the relationship between fasting blood glucose and each WC, BMI, and W: HR. P values less than 0.05 indicate statistical significance. ${ }^{8}$

\section{Results}

A total of 31 adults participated in the study. Of the 31 adults, 8 were male, and 23 were female. Similarly, 8 participants were overweight $\left(25 \mathrm{~kg} / \mathrm{m}^{2} \leq \mathrm{BMI}<30 \mathrm{~kg} / \mathrm{m}^{2}\right)$ and 23 were normal weight $\left(18.5 \mathrm{~kg} / \mathrm{m}^{2} \leq \mathrm{BMI}<25 \mathrm{~kg} / \mathrm{m}^{2}\right)$. No subjects were obese. Because of the lack of difference between the normal weight and overweight individuals, data are presented as one study population group (BMI of $\left.18.5-29.9 \mathrm{~kg} / \mathrm{m}^{2}\right)$. The mean and standard deviations of age, weight, height, BMI, WC, HC, W: HR, and FBG are presented in Table 1. Statistical analysis showed that measures of WC, BMI, and W: HR was not significantly correlated with FBG in the population sampled. Pearson's correlation coefficients of FBG with WC, BMI, and W: HR is shown in Table 2.

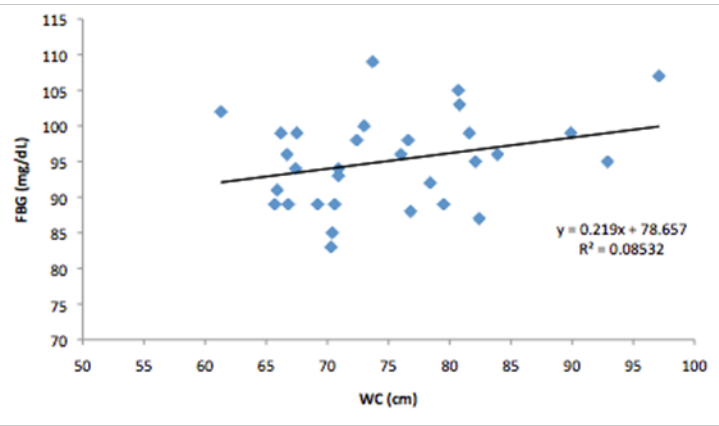

Figure I Correlation of FBG and WC in healthy adult population.
Table I Characteristics of total subjects $(n=3$ I)

\begin{tabular}{|c|c|}
\hline Characteristic & Mean士SD \\
\hline Age (years) & $26 \pm 6.44$ \\
\hline Weight (kg) & $64.67 \pm 12.23$ \\
\hline Height (m) & $1.67 \pm 0.105$ \\
\hline BMI $\left(\mathrm{kg} / \mathrm{m}^{2}\right)$ & $22.98 \pm 2.70$ \\
\hline$W C(\mathrm{~cm})$ & $75.08 \pm 8.54$ \\
\hline $\mathrm{HC}(\mathrm{cm})$ & $90.46 \pm 6.86$ \\
\hline W: HR & $0.83 \pm 0.082$ \\
\hline FBG (mg/dL) & $95 . I \pm 6.4 I$ \\
\hline Activity Level ${ }^{8}$ & \# of Subjects \\
\hline $\begin{array}{l}\text { Inactive (no formal physical activity but includes activities } \\
\text { of daily living) }\end{array}$ & 4 \\
\hline $\begin{array}{l}\text { Moderately Active (equivalent to walking I. } 5 \text { to } 3 \text { miles } \\
\text { per day at } 3 \text { to } 4 \text { miles per hour plus activities of daily } \\
\text { living) }\end{array}$ & 8 \\
\hline $\begin{array}{l}\text { Active (equivalent to walking more than } 3 \text { miles per day at } \\
3 \text { to } 4 \text { miles per hour plus activities of daily living) }\end{array}$ & 19 \\
\hline
\end{tabular}

a. BMI, body mass index;WC, waist circumference; HC, hip circumference; W:HR, waist-to-hip ratio; FBG, fasting blood glucose

b. All values are Mean \pm SD unless stated otherwise

Table 2 Comparisons of FBG with common measures of obesity

\begin{tabular}{rlll}
\hline $\begin{array}{l}\text { Pearson's } \\
\text { correlation }\end{array}$ & FBG vs.WC & FBG vs. BMI & FBG vs.W:HR \\
\hline $\mathrm{r}$ & 0.2921 & 0.3154 & 0.2036 \\
$\mathrm{P}$ & 0.1108 & 0.084 & 0.2718 \\
\hline
\end{tabular}

\section{Discussion}

There are a few limitations within this study that could cause the lack of statistical significance. First of all, this pilot investigation included a small sample size. In the future larger sample sizes should be used to allow the separate analyses of men versus women, different age groups, and normal weight and overweight. Second, a majority of the participants were at least moderately active according to the classification in the Federal Physical Activity Guidelines. ${ }^{9}$ Since physical activity is an intervention known to improve FPG, future studies in this population should include an analysis of those who are sedentary.

\section{Conclusion}

Overall, we conclude that neither WC, nor W: HR, are suitable risk determinants for Type 2 diabetes in the physically active, healthy, young adult population. Individuals with other risk factors for developing prediabetes or Type 2 diabetes should receive the education necessary to induce lifestyle changes aimed at reducing their risk. In the future, larger sample sizes, or physically inactive participants, should be examined to determine waist circumference and Type 2 diabetes risk in the normal weight population.

\section{Acknowledgements}

This material is supported by the National Institutes of Health program, Nevada INBRE. A special thank you to Jessica Knurick for 
the encouragement to pursue this endeavor, as well as her guidance. Thank you to Grace MacDonald and the UNLV exercise physiology lab for providing a space to perform data collection, as well as Meagan Levitt and Anna Gingrich for data collection assistance.

\section{Conflict of interest}

The author declares no conflict of interest.

\section{References}

1. Centers for Disease Control and Prevention (CDC). National Diabetes Prevention Program-About Prediabetes and Type 2 Diabetes.

2. US Department of Health and Human Services. Risk Factors for Type 2 Diabetes. USA: The National Institute of Diabetes and Digestive and Kidney Diseases Health Information Center; 2018.

3. Freemantle N, Holmes J, Hockey A, et al. How strong is the association between abdominal obesity and the incidence of type 2 diabetes? International Journal of Clinical Practice. 2008;62(9):1391-1396.
4. US Department of Health and Human Services. Assessing your Weight and Health Risk. USA: National Institutes of Health, National Heart, Lung, and Blood Institute; 2018.

5. Estimates of diabetes and its burden in the United States. USA: Centers for Disease Control and Prevention, National Diabetes Statistics Report; 2017.

6. Mainous AG, Tanner RJ, Jo A, et al. Prevalence of Prediabetes and Abdominal Obesity among Healthy-Weight Adults: 18-Year Trend. Ann Fam Med. 2016;14(4):304-310.

7. WHO. Waist Circumference and Waist-Hip Ratio: Report of a WHO Expert Consultation. Geneva, Switzerland; 2008. p. 1-39.

8. US Department of Health and Human Services. A Healthier You. 2018.

9. Department of Health and Human Services. Physical Activity Guidelines for Americans. Washington, USA; 2008. 